\title{
The Importance of Cultural Infiltration in Chinese Language Teaching
}

\author{
WU Wei \\ North China University of Technology, Beijing, China
}

\begin{abstract}
When teaching international students Mandarin, teachers should not just teach the language, grammar, but the Chinese cultural dissemination needs to be included as well, which is extremely important because the language reflects the cultural exchange. Culture is a necessary condition for language learning, which can help students better understand Chinese. Teaching foreigners Chinese culture is not only in the classroom, but also in the second class (out of the classroom) which can help students to experience culture and promote cultural dissemination effectively. In this paper, the author is going to introduce the $5 \mathrm{C}$ curriculum standards that is developed by the US government, to mention the purpose of cultural education, and as well as to discuss about the importance of cultural infiltration during both the class and the second class by using some examples.
\end{abstract}

Keywords: Chinese teaching, cultural infiltration, the second class

\section{Introduction}

With the development of economic globalization and the improvement of China's international status, learning Chinese is set off all over the world. Overseas universities offer professional Chinese study and the number is increasing every year. Correspondingly, teaching Chinese as a foreign language also shows the fiery scene. Therefore, how to effectively promote the Chinese language in the world, so that more and more people want to learn Chinese, to say Chinese? It should begin with the United States 5C standards. This paper elaborates on teaching Chinese culture as one of the standard 5Cs.

Hanban has established and funded a lot of Confucius Institute and Chinese language class, and also has trained many Chinese teachers. In addition, Hanban has donated a lot of books and video materials for overseas Chinese schools. Each year Hanban organizes the General Assembly worldwide. Besides this, Hanban will select Chinese guest teachers, Critical Languages Project teachers, Confucius Institute teachers, and so on. Clearly, national efforts and initiatives in the promotion of Chinese language and culture are significant.

In China, people also began learning Chinese. Arts and Law College, College of Humanities, Chinese Academy, International College, etc., have set up Chinese international education as a major. Not only language schools and comprehensive universities offer this major, even some technology universities have begun to set up this profession. The students are pride of being admitted to the profession.

In other countries, a growing number of universities offer Confucius Institute. In primary and secondary

WU Wei, instructor, MBA, Chinese Department, North China University of Technology. 
schools, more schools apply to set up Chinese as a foreign language subject every year; and more principals apply for "Overseas Principals Delegation" project to China to experience the Chinese language, culture, and traditions. Therefore, the enthusiasm of Chinese language learning is increasing hot in the country and all over the world.

\section{Chinese International Teaching Standards}

It is much easier for Chinese to learn their language than foreigners, but how do teachers teach foreigners Chinese well?

In 1996, the US government developed a national curriculum standards-“Foreign Language Learning Standards: Preparing for the 21st Century” (see Figure 1); the standards are national curriculum standards which were jointly developed by the US Department of Education and Multiple Foreign Language Education Association, and were amended and reprinted in 1999, and not only adding a number of language learning objectives, but also meeting the needs of the political, economic, cultural and international exchanges. The five core themes of the standards are: (1) verbal communication, (2) cultural communication, (3) connecting knowledge, (4) the ability to compare, and (5) community activities.

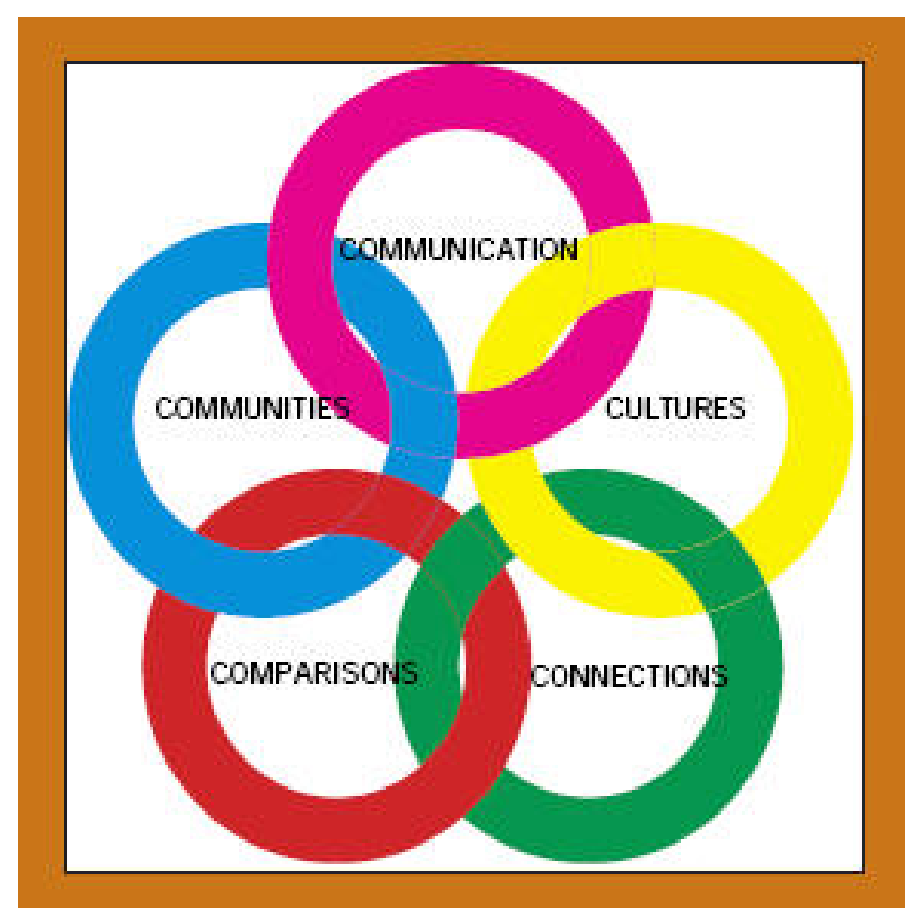

Figure 1. American five Cs standards.

First of all, let the author explain these five core themes. First, language communication, refers to using language (in this case as a foreign language) in interpersonal communication to communicate, interpret, and translate information on a variety of topics; second, cultural communication, refers to enhancing the understanding of the target culture through three aspects which are the cultural values, cultural practices, and cultural products; third, connecting knowledge, refers to emphasizing foreign language (in this case as a foreign language) linking with other disciplines, and studying to extend the knowledge of other disciplines through 
foreign language (in this case as a foreign language); fourth, comparison capability, refers to comparing the target language with the mother tongue to learn and understand more about the target language and culture; fifth, community activities, refers to the language being used in internal and external environment, in which people have fun in the process, and then become lifelong learners. The five core themes mentioned above promote, penetrate, and support each other, and cannot be separated.

Secondly, after understanding the five core themes, the teachers should strive to do every aspect in teaching Chinese. In the 21st century, with the economy's globalization, in order to make a foreign language education meet the needs of economic construction and social development, the teachers should actively convert foreign language teachers' roles in teaching, from a knowledge transfer to a facilitator of students' organizer, guide and participants; the teachers should also make the classroom active starting from the students' interests, motivation, and life experience. Here are some simple examples:

(1) The teacher introduced new courses by simple questions, such as "Do you like to eat?" in order to understand the students' eating preferences.

(2) Teachers taught new words using different images, and knew the results of the students preview by way of questions and answers.

(3) Students were divided into two groups; they were asked to understand each other's diet hobbies. The teacher would choose one group to do the show. After this part of the exercise, the teacher asked each student to introduce their companion's food-loving.

(4) The teacher showed some pictures or videos about a variety of Chinese diet to students through PPT, such as Beijing roast duck and hot pot. There are also some other delicious food and fun entertainment places.

(5) The teacher asked the students to write an essay of 150 words after school, which needed to introduce their father and mother's diet hobbies.

From the above examples, it is clear that the five core themes have been implied during the whole teaching process:

(1) Language Communication: In this lesson, students can easily communicate with other people about eating hobbies.

(2) Cultural Communication: In this lesson, students have some understanding of the Chinese ways to eat and leisure venues.

(3) Connecting Knowledge: In this lesson, students can simply understand the traditional diet, such as Beijing roast duck and hot pot.

(4) Comparing Capacity: In this lesson, students can compare their own experience and the Chinese people's eating habits, then they can know their differences about their diets in a casual way.

(5) Community Activities: In this lesson, students can introduce ordinary Chinese people's eating habits to his family, friends, and relatives in their mother tongue.

From the above examples, it seems that teaching is not completely independent from these four skills which are "listening, speaking, reading, and writing", but it is more practical to integrate them into the communication environment. These five core themes foster communicative competence, and build a comprehensive education system which is the perfect combination of teaching theory and practice. As long as these five core themes are used perfectly in teaching, so it believes, to teach foreigners Chinese is no longer a difficult task. Of course, not 
every class contains 5C standards, however, almost every class is more or less related to the Chinese culture. Language is an important part of culture. Language and culture cannot be separated. Different languages reflect different culture; different languages have different cultural backgrounds. China has five thousand years' history and culture, therefore, when teachers teach the culture in the classroom, they should not only make the classroom vivid, but also increase the students' interest, so that students are better able to grasp the Chinese language that they are supposed to learn.

\section{The Purpose of Cultural Education}

In order to teach foreigners Chinese well, teachers must first understand the ultimate goal of learning Chinese. The specific purposes of learning Chinese are diverse: some for professional purposes in order to be a Chinese teacher, an English translator, or to do research work; some for professional tools purposes in order to use the language in foreign trade; some for academic purposes in order to engage in research; some for the purpose of education in order to have further education or to improve student literacy, etc.. Purposes are different, but it is clear that foreign students learning Chinese is to seek cross-cultural communication and understanding, and to realize knowledge of another culture's attitude to life, customs, psychology, ways of the thinking, values, etc.. These learning objectives are all related to culture. Therefore, whether Chinese language teaching and cultural infiltration is good or not directly relates to the learner's ability to achieve the purpose of language learning. Another purpose is to make the cultural learners understand cultural connotations, master the correct cultural knowledge, and convert it to cross-cultural communication skills. Therefore, in order to grasp the authentic Chinese, the only way is to be familiar with the Chinese language and culture.

\section{The Importance of Teaching Culture}

The word "culture" is very rich, and it encompasses many areas, which can be affected in lots of things. Culture is reflected not only in the classroom, but also in the second classroom. Here the author talks about the importance of teaching culture in the classroom and the second classroom.

\section{Teaching Culture in the Classroom}

To promote culture in language learning. In the classroom, speaking from the perspective of language, Chinese and Western languages are different. Cultural infiltration can help students understand what they have learned in the classroom more correctly. For a familiar example, there is only one word-“uncle” in English, but there are a lot of different sayings for "uncle" in Chinese because this is related to the Chinese tradition. Since the ancient times, China pay attention to the clan system, so both parents and relatives are clearly identified, and all this will make the Westerners do not understand. For another example, in the West, people even did not have the appropriate title for brothers and sisters, and uniformly called "brother" and "sister" until the words were translated into Chinese language, while brothers were called "old brother", "little brother". In fact, "old brother" is translated into "big brother", "little brother" is translated into "small brother", can anybody say it incorrectly? Language translation errors are caused by different cultures. Thus, the cultural difference between the two languages is a very important factor in learning Chinese. If you cannot understand and master the Chinese culture, you will not be able to speak an authentic Chinese.

To permeate culture in Chinese language teaching. Cultural penetration in the teaching of Chinese 
characters can make the teaching achieve good results. Learning Chinese characters are usually the most difficult points to foreign students. In the eyes of many students, Chinese characters are incredible symbols like the Bible. But characters have pictographic and ideographic characteristics. The teachers should make full use of Chinese characters owning vivid characteristics to help students understand the Chinese culture, so that students can feel the Chinese characters in the inherent charm. For example, in zero beginning class, when explaining the character of "sit”- “坐”, the teacher can play a character piece, with storytelling, dynamic images, vividly explaining the two persons sitting on the ground has become “sit”—“坐”. Another example, when teaching “wood”—“木”, “branch”—“林”, “forest”—“森”, teachers can use pictures to show students that one tree is “木”, two trees will be “林”, and three trees together will become “森”. It not only enables students to remember Chinese characters effectively, but also makes classroom teaching full of fun and vitality in the cultural atmosphere. Such cultural infiltration teaching methods of Chinese characters can help students to understand the characters in a relaxed mood, meanwhile can allow students to understand the Chinese characters characteristic behind the rich cultural connotations, which helps to improve the learner's memory.

\section{The Necessity of Cultural Experience in the Second Class}

Traditional classroom teaching will teach students to master a set of Chinese rules, and of course can teach students some of the Chinese culture, but when they are out of the classroom dealing with the Chinese people, there will always encounter a lot of problems. They feel that what Chinese people say is not what they have learned in class, and they do not understand the Chinese people. The facts tell people that simple classroom teaching cannot meet the needs of teaching foreigners Chinese; the second classroom teaching must be opened that can help to improve teaching effectiveness: a variety of cultural experiences which include cultural tourism, Chinese culture corner, Chinese table, International Cultural Festival, Chinese folk activities, etc..

Language and culture are closely connected. Chinese teaching and cultural infiltration of the second class have the following effects.

Cultural tourism. Cultural tourism is a widely popular activity. Today, the educational "cultural tourism" is more and more popular. Through cultural tourism, students can go out of the classroom. Students participating in tourism is an effective way to expand horizons, to increase knowledge, which can help students understand and digest what they have learned in class, and also can help them to deepen the knowledge of the impression. Cultural tourism, as a modern form of education outside the classroom, makes students also broaden their knowledge, complement and promote classroom learning. Cultural tourism, as an important aspect of quality education, drags more and more people's attention, which is also a noteworthy foreign language teaching way.

Chinese culture corner. When foreign students come to China to study Chinese, their dormitories are isolated from the rest of the campus, so it is difficult for them to communicate with Chinese students of the similar age, which means they will have very few opportunities to practice Chinese. Therefore, many foreign students are eager to have the opportunity to practice oral Chinese, and want to understand China's history, culture, and customs. To achieve this purpose, it is not enough to just limit the classroom instructions, but "going out" is also a good method to learn the language, to use the language, thus Chinese culture corner meets the expectations of the students. Chinese cultural corner can enrich students' lives on campus after school.

Chinese table. In China, foreign students' studying and living are inseparable. Almost all foreign students 
are more willing to stay together with their own country's classmates, and few students can be with Chinese very often. At this time you need Chinese table. Students and teachers communicate freely while dining with Chinese during Chinese table once a week, which not only lets students have more opportunities to practice speaking and enhance students' communication ability. On the Chinese table, students can also understand more about the Chinese culture, Chinese people's customs and habits.

International cultural festival. International cultural festival will better mobilize the enthusiasm of the students. When students watch others' performance, they can also watch and know their country's culture; maybe then they are interested in understanding the countries, especially because they are in China, besides the common lives, the international festival performace can help the foreign students understand more about China's culture, which is a win-win activity.

Folk culture. Appropriate folk culture is also essential. For example, learning and experiencing the culture of paper-cut, making foreign students participate in folk games, etc.. As some folk customs in the classroom are very difficult to encounter, foreign students can truly appreciate the connotation of Chinese folk culture and fun only by participation into them, and all this cannot be achieved just from the text book, so the second classroom is necessary and important.

\section{Conclusion}

Culture affects the language, and the language reflects the culture. Chinese language teaching is a cross-cultural communication activities. In class, it includes voice, vocabulary, grammar, characters, and chapters. However, the second class focuses on interests, hobbies, self-confidence, and emotional attitude of cooperation, which is a useful means that can improve the students' learning process and learning outcomes effectively. Besides this, the second class also fills the vacancy of culture in the knowledge of the language in the classroom. Therefore, in addition to language teaching, it is necessary to organize the colorful second class in order to meet the different communicative purposes, and especially in the second classroom, cultural infiltration improves the students' interest in Chinese language and culture, and also promotes the development of Chinese language teaching.

\section{References}

American Council on the Teaching of Foreign Languages (ACTFL). (1996). Standards for foreign language learning: Preparing for the 21st century. Kansas: Allen Press Inc. USA.

HUANG, X. Y. (2002). Foreign language classroom teaching art. Beijing: Beijing Language University Press.

LI, J. C., \& ZHAO, C. P. (2011). Chinese folk culture. Beijing: Haichao Press.

LIU, X. (2002). Teaching Chinese as a second language. Beijing: Beijing Language University Press.

Ning, Y. C., \& Montanaro, S. J. (2011). Chinese language and culture. New Haven: Yale University Press.

Swift, J. S. (2008). Foreign language competence and international business: A cultural approach. Liverpool: Liverpool Academic Press.

YANG, H. Y. (2008). Classroom theory and practice. Beijing: Beijing Language University Press.

ZHOU, S. Y. (1998). Foreign language teaching and culture. Beijing: Beijing Language and Culture University Press. 